\title{
Acacia Pollen Associated with the Abandonment of a Prehistoric Mimbres Archeological Site.
}

\author{
M.W. Pendleton, ${ }^{*}$ B.B. Pendleton, ${ }^{* *}$ and T. Stephens* \\ *Microscopy \& Imaging Center, Texas A\&M University, College Station, TX. 77843. \\ **Division of Agriculture, West Texas A\&M University, Canyon, TX. 79016.
}

A high concentration of Acacia pollen grains was recovered from a soil sample taken from Room 60 , one of the last rooms occupied at the NAN Ranch Ruin, a prehistoric Mimbres archeological site occupied from 550 to 1150 A.D [1]. One hundred and twenty-eight soil samples were tested from eleven rooms at the NAN Ranch Ruin for pollen grains and spores [2].

Lycopodium spores were added to each $20 \mathrm{ml}$ soil sample to enable pollen and spore concentration levels to be calculated. Soil samples were placed in hydrochloric acid, rinsed, and screened through 200 micrometer mesh. Following treatment in hydrofluoric acid, rinsing, and sonication, the residues were placed in zinc bromide with a density of 2.0 and the heavy fraction was discarded. The light fraction containing pollen and spores was then acetolysed, rinsed in alcohol, and mounted on slides. The extracted pollen grains were identified by observation with a Swift compound light microscope at $100 x$ to $1000 x$ magnifications.

The concentration of Acacia pollen recovered from sample 12 in Room 60 at the NAN Ranch Ruin was far greater than the average concentration of Acacia pollen of other samples taken from Room 60 (Fig. 1). Such a high pollen concentration implies that Acacia flowers were associated with sample 12. Moore notes that Acacia flowers and leaves were used by southwestern Indians as a very effective sedative [3]. Because psychoactive plant materials such as harvested Datura seeds have been recovered at another Mimbres archeological site [4], this discovery of Acacia pollen may also indicate prehistoric psychoactive alkaloid utilization. While the species of Acacia pollen recovered from sample 12 cannot be determined, three alkaloids have been extracted from an Acacia species currently found in northeastern Mexico [5]. It is not clear what association may be made between the use of Acacia flowers and site abandonment [6].

\section{References:}

[1] H.J. Shafer and C.K. Judkins, Arch. Invest. at the NAN Ruin, 1996 Season. Texas A\&M Univ. Anthropology Research Lab. Report No. 11, College Station, Texas, 1997.

[2] M.W. Pendleton, Late Holocene Paleoenvironment and Human Ecology in S.W. New Mexico.

Ph.D. Dissertation, Dept. of Anth., Texas A\&M Univ., College Station, Texas, 1993.

[3] M. Moore, Medicinal Plants of the Desert and Canyon West, Museum of New Mexico Press, Santa Fe, 1989.

[4] R.A. Yarnell, El Palacio 66 (1959) 176.

[5] H.R. Adams and B.J. Camp, Toxicon 4 (1966) 85.

[6] Funding for this research was provided by a Texas A\&M University College of Liberal Arts

Dissertation Award, a Texas A\&M University Academic Excellence Award, and a Texas A\&M University Association of Former Students Mini-grant. 


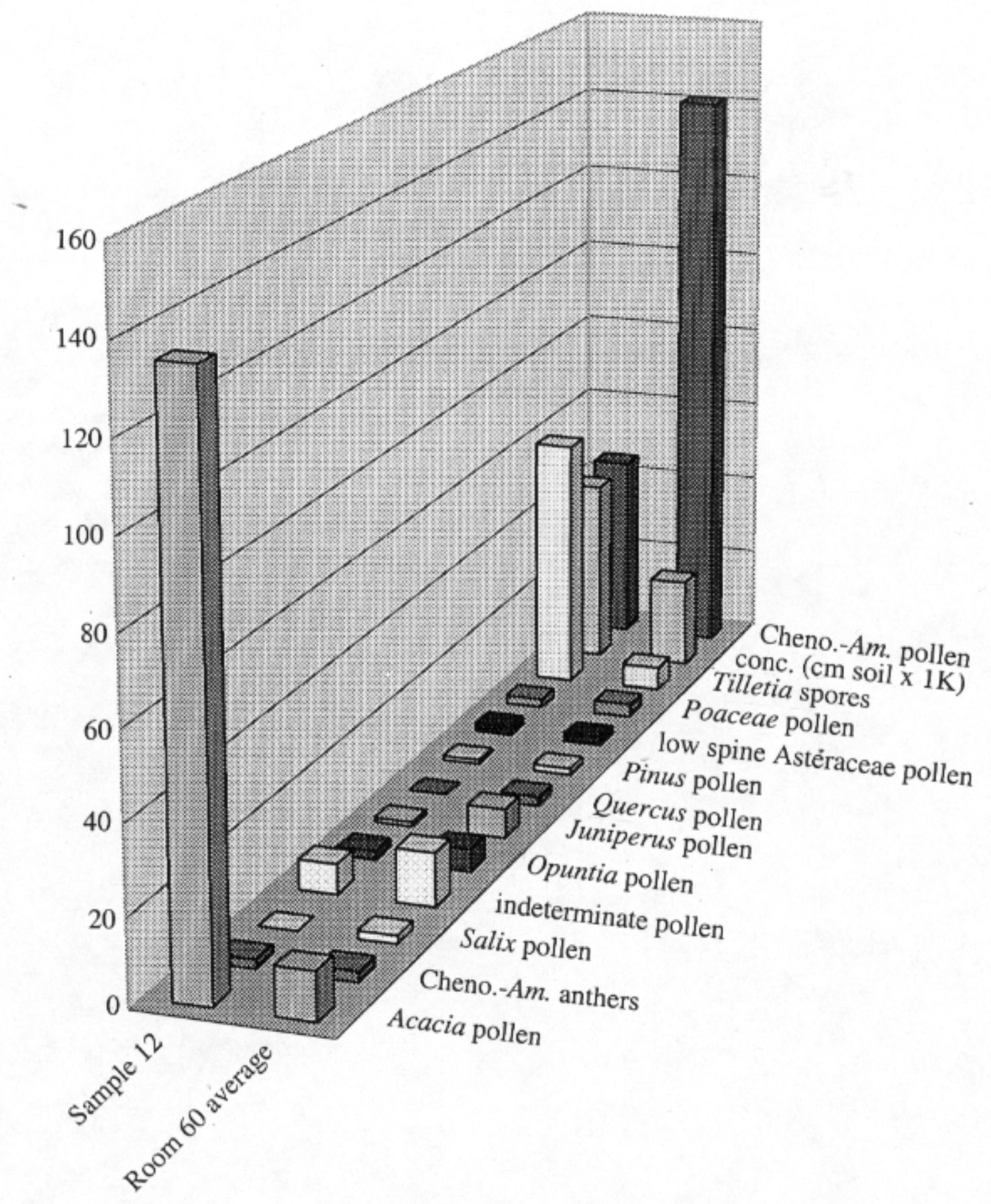

FIG. 1. Graph of pollen and spore total counts and concentration levels for sample 12 and the average for room 60. Cheno.-Am. designates pollen of the Chenopodiaceae family and the Amaranthus genus which are not distinguishable from one another using light microscopy. 
https://doi.org/10.1017/S1431927603443249 Published online by Cambridge University Press 